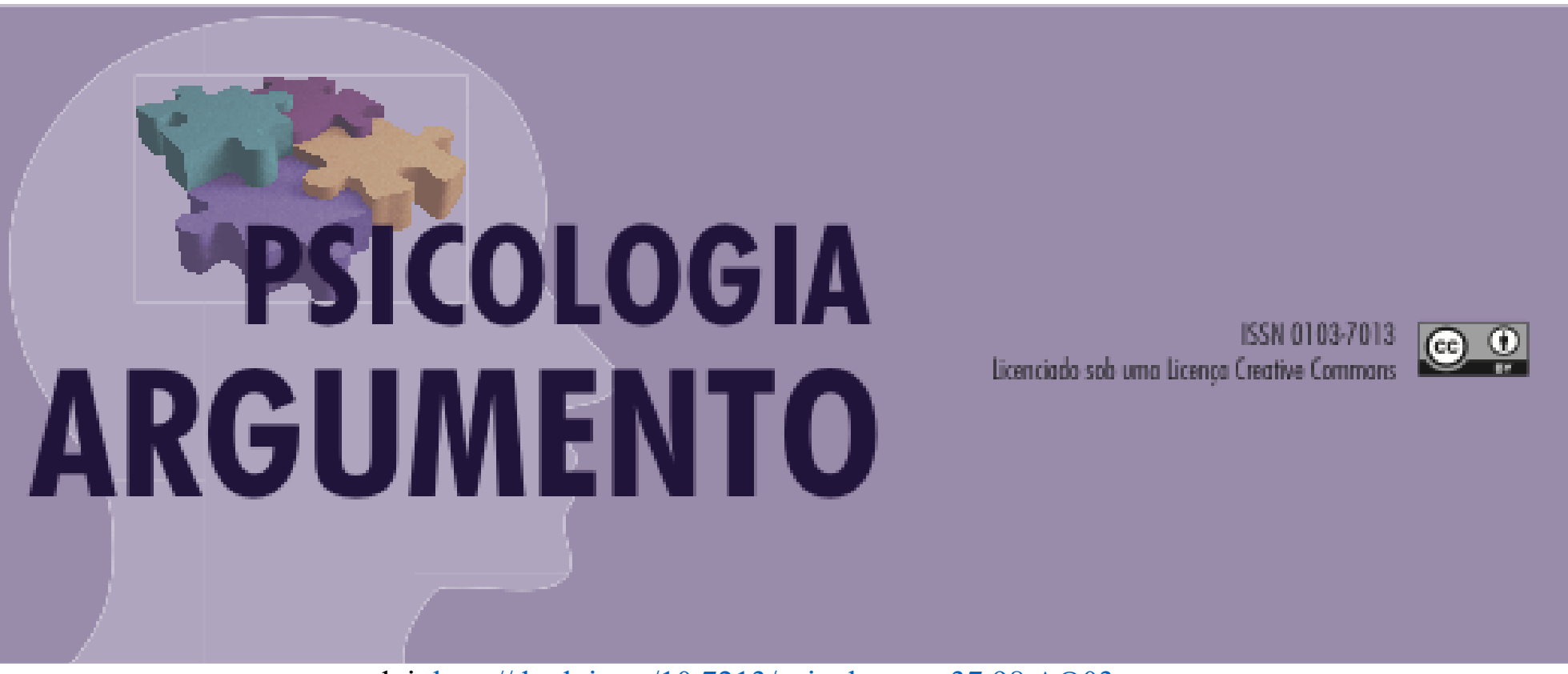

doi: http://dx.doi.org/10.7213/psicolargum.37.98.AO03

\title{
Síndrome de burnout e saúde ocupacional em educadores de uma
}

\section{unidade pré-escolar}

Burnout syndrome and occupational health in educators in a pre-school unit

Sindrome de burnout y salud en educadores de una unidad preescolar

\section{Rodrigo Diaz de Vivar y Soler}

Fundação Universidade Regional de Blumenau, e-mail: rsoler@furb.br

http://orcid.org/0000-0001-7286-3129

Débora Renata de Oliveira Gomes

Fundação Universidade Regional de Blumenau, e-mail: debyrenata10@hotmail.com

http://orcid.org/0000-0003-1692-8244

\section{Resumo}

A Síndrome de Burnout é uma doença que causa graves danos à saúde mental e física das pessoas atingindo a esfera social e profissional, deixando-as impossibilitadas de exercerem suas atividades profissionais. Existem diversos estudos sobre a Síndrome de Burnout em educadores, porém poucos estudos foram publicados a respeito deste tema em 06 professores de educação infantil. Nossa pesquisa aplicou o Job Diagnostic Survey para avaliar se existem indicadores da síndrome em uma escola de educação infantil no Vale do Itajaí. Os resultados mostram um alto nível de exaustão emocional e despersonalização, indicadores da Síndrome de Burnout. Em contrapartida existe um elevado nível de realização pessoal, o que pode indicar um grau de sofrimento psíquico alto, acompanhado de uma satisfação pelo seu trabalho.

Palavras-chave: Síndrome de burnout; educação Infantil; psicologia; saúde ocupacional. 


\begin{abstract}
The Burnout Syndrome is a disease that causes great injury to mental and physical health of people. Reaching social and professional sphere, leaves them unable to perform their professional activities. There are several studies about Burnout Syndrome in educators, but few studies have been published on this topic in early six childhood teachers. Our research applied the Job Diagnostic Survey to assess whether there are indicators of the syndrome in a preschool in Vale do Itajai. The results show a high level of emotional exhaustion and depersonalization, indicators of Burnout Syndrome. On the other hand, there is a high level of personal fulfillment, which may indicate a high degree of psychological distress, accompanied by a satisfaction with your work.
\end{abstract}

Keywords: Burnout syndrome; early childhood; psychology; Occupational health.

\title{
Resumen
}

El Síndrome de Burnout es una enfermedad que causa graves daños a la salud mental y fisica de las personas, llegando a la esfera social y profesional, dejándolas incapaces de ejercer sus actividades profesionales. Existen varios estudios sobre el Sindrome de Burnout en educadores, pero se han publicado pocos estudios sobre este tema en 06 docentes de educación infantil. Nuestra investigación aplicó la Encuesta de diagnóstico de trabajo para evaluar si hay indicadores del sindrome en un jardín de infantes en Vale do Itajai. Los resultados muestran un alto nivel de agotamiento emocional y despersonalización, indicadores del síndrome de Burnout. Por otro lado, hay un alto nivel de satisfacción personal, lo que puede indicar un alto grado de angustia psicológica, acompañado de satisfacción con su trabajo.

Palabras clave: Síndrome de burnout; educación Infantil; psicología salud Ocupacional.

\section{Introdução}

A rotina diária de trabalho somada ao excesso de responsabilidades e metas cada vez maiores, pode contribuir para a geração do estresse para o profissional. Segundo Mota, Alencar e Tapety (2016, p. 2):

\begin{abstract}
O conceito de estresse foi escrito pela primeira vez por Hans Selye em 1936 e desde então vem sendo utilizados para diversas situações externas. Para o autor, o termo stress foi discutido durante muito tempo a fim de entendê-lo e conceituá-lo ainda que disseminado com muitos conceitos discordantes entre autores. Portanto, pode-se dizer que esse termo já foi muito popularizado em relação ao termo Burnout, entretanto, deve-se considerar como um problema de saúde pública, visto que a sua cronicidade contribui para o desencadeamento da síndrome de Burnout.
\end{abstract}

A palavra Burnout é proveniente do inglês burn out que significa queimar, resultado de quando o sujeito chega ao seu limite e não possui mais energia. A Síndrome de Burnout é uma patologia que provoca desgaste físico e emocional ao sujeito, devido à carga excessiva de trabalho, tendo como sintomas físicos dor de cabeça, enxaqueca, cansaço, entre outros, desenvolvendo também sintomas psicológico, comportamentais e defensivos. 
O foco da nossa pesquisa foi o de desenvolver um estudo empírico em uma escola da rede municipal de ensino no Vale do Itajaí objetivando analisar a possível relação da Síndrome de Burnout com a atividade educacional. É importante, sinalizarmos a relevância desse trabalho nos estudos sobre Psicologia e Educação como forma, de se procurar desenvolver a partir das relações interpessoais no mundo do trabalho, tanto uma leitura, como uma possibilidade de intervenção frente as práticas laborais. Conforme apontam os estudos de Carlotto (2014) e Andrade e Cardoso (2012), os indicativos e estudos sobre a síndrome de burnout acabam por sinalizar os aspectos relacionados à busca por melhores condições no ambiente de trabalho e, consequentemente, na melhoria da qualidade de vida dos docentes desde a Educação Básica até o Ensino Superior.

Esses estudos mostram-se relevantes por revelarem o grau de adoecimento dos educadores, e deste modo, justifica-se a necessidade da elaboração, por parte da psicologia, por análises a respeito de um tema tão relevante. Desse modo, é importante destacar que um estudo sobre a relação entre a síndrome de burnout com trabalhadores da educação infantil justifica-se pelos fatores de risco inerentes a uma atividade profissional tão desgastante e pouco valorizado.

O objetivo da nossa pesquisa foi o de identificar, por meio da aplicação do Maslach Burnout Inventory, a possível incidência da Síndrome de Burnout em um Unidade Pré-Escolar em uma escola localizada na Região do Vale do Itajaí.

Por ser uma doença que causa graves danos à saúde mental e física dos educadores deixando-os impossibilitados de exercerem seu papel, o burnout segundo Pereira (2003, p. 2):

O trabalho docente vem sofrendo grandes alterações durante a história recente do Brasil, marcadas por uma perda de prestígio social, remuneração injusta, condições de trabalho degradantes, enfraquecimento sindical, dentre outros, sendo que tanto a sua subjetividade como aspectos políticos e sociais precisam de maior compreensão e cientistas.

Dessa forma, apontamos, em um primeiro momento, as articulações teóricas acerca da procedência do burnout em educadores, para, em um segundo momento, apresentarmos o método de trabalho e os resultados da nossa intervenção em uma unidade pré-escolar localizada no Vale do Itajaí.

A síndrome de burnout e a saúde ocupacional

A passagem do capitalismo industrial para o capitalismo financeiro tem levado a uma profunda transformação das relações dos sujeitos com o mundo do trabalho. A partir 
de uma lógica radicalmente oposta ao capitalismo fabril, os novos sistemas econômicos, as constantes reformas administrativas e o aumento gradativo do desemprego, mesmo em países muito industrializados têm levado muitos profissionais a adoecerem física e mentalmente. Soma-se a isso, as jornadas cada vez mais excessivas de trabalho, a precarização das legislações trabalhistas e o recente crescimento da Indústria 4.0 como elementos catalisadores do sofrimento laboral. Em resumo, geralmente, o professor possui uma carga horária excessiva de trabalho com poucos recursos, levando este profissional a vivências estressantes, expectativas e projetos existenciais cada vez menos potencializadores, desgastando-o cada vez mais, fazendo com que ele não suporte mais as suas frustrações laborais.

No caso dos professores é correto afirmarmos que eles, convivem diariamente com a pressão inerente ao ofício da educação. A falta de remuneração adequada e reconhecimento pela atividade que exercem, acaba desanimando-os e, por vezes, esses profissionais acabam por buscarem formas de complementação da renda, ou até mesmo, continuando a exercer sua profissão após sua aposentadoria, para assim ganhar um salário digno, pois conforme aponta Oliveira (2014, p. 1132):

O professor, diante das variadas funções que a escola pública assume, tem de responder a exigências que estão além de sua formação. Muitas vezes esses profissionais são obrigados a desempenhar funções de agente público, assistente social, enfermeiro, psicólogo, entre outras. Tais exigências contribuem para um sentimento de desprofissionalização, de perda de identidade profissional, da constatação de que ensinar às vezes não é o mais importante.

Opinião semelhante possuem Tostes ett alii, (2018), para quem, a carga horária excessiva e uma demanda maior que consegue suportar, acabam por tornar o professor um forte candidato para o desenvolvimento do burnout, já que, ao longo da sua trajetória profissional ele acaba se deparando com muitas situações de estresse, contrariando as expectativas profissionais da realidade.

O termo da palavra burnout, foi utilizado pela primeira vez por Schwartz e Will (1953), no caso que foi conhecido por Miss Jones, que descreveu uma enfermeira do ramo da psiquiatria que se via iludida com seu trabalho. Alguns anos depois, em 1969, desenvolve o conceito de staff burn-out para designar os primeiros sintomas relacionados ao esgotamento pelo trabalho. Mais tarde, em 1974, o termo foi retomado pelo psicólogo Herbert J. Freudenberger, que descreveu um quadro clínico dos profissionais de uma clínica de dependentes químicos em Nova Iorque. Os profissionais que ali atuavam, tinham a visão de que os pacientes eram pessoas que não necessitavam mais de suas 
ajudas. Com isso, concluiu em seu trabalho a definição de alguns sintomas, como fadiga, irritabilidade, perda de motivação, sobrecarga, depressão, inflexibilidade e rigidez. Desse modo, conforme aponta Castro (2013, p. 51):

Desde Maslach e Jackson (1981), o fenômeno de burnout vem sendo demarcado a partir de três dimensões essenciais: a exaustão emocional, a despersonalização e a perda da realização pessoal. Dessas três dimensões, sem dúvida, a exaustão emocional é aquela que se evidencia como fundamental no desenvolvimento de burnout, sendo responsável pelo desencadeamento das duas outras. Segundo uma revisão teórica feita por Leiter (1993), é a partir do momento em que o sujeito encontra-se esgotado em suas energias psíquicas e exausto para continuar seu trabalho, que passaria a despersonalizar suas relações com os outros e perderia a realização pessoal.

Maslach foi quem popularizou o conceito de burnout. Maslach, pesquisadora da Universidade da Califórnia e psicóloga social, foi quem compreendeu primeiramente que pessoas com a Síndrome de Burnout demonstravam atitudes negativas e distanciamento nas suas práticas profissionais.

Na década de 80, surge o instrumento Maslach Burnout Inventory (MBI), escala que apresenta características e propriedades psicométricas, sendo uma das escalas mais utilizadas nos dias atuais. Com o surgimento da escala, a pesquisa que inicialmente era apenas realizada nos Estados Unidos, começa a chamar a atenção dos europeus, fazendo com que também desenvolvessem estudos sobre a síndrome.

A Síndrome de Burnout está relacionada ao desgaste físico e emocional, causado pelo excesso de trabalho. Ela pode afetar o ambiente de laboral e também o ambiente familiar e, se dá, pela cronicidade de desequilíbrios emocionais devido a maiores exigências no serviço, está sendo desproporcional ao que indivíduo pode contribuir (Mota; Alencar; Tapety, 2016).

Segundo Fonte (2011), a definição de burnout pode ser considerada como um estado psicológico negativo, persistente, relacionado com o trabalho, que ocorre em indivíduos e que se caracteriza pela exaustão, sofrimento, reduzida motivação e eficácia, e pelo desenvolvimento de atitudes ou comportamentos disfuncionais na sua vida.

A caracterização da síndrome é agrupada em três dimensões, como um conjunto de sinais, dentre os quais podem se destacar a elevada exaustão e despersonalização emocional, despersonalização e baixa realização no trabalho. O primeiro traço é a exaustão emocional que pode manifestar-se de forma física e/ou psíquicas. Considerada o núcleo da síndrome, ela tem como características a falta de energia, a falta de entusiasmo e o sentimento de esgotamento. Estes sentimentos podem ser somados com o 
sentimento de frustração e tensão, pois os profissionais começam a perceber que não conseguem mais depender de sua energia para o exercício de suas atividades laborais.

O segundo sinal da síndrome, é a despersonalização que se caracteriza pela insensibilidade emocional, sendo uma reação imediata, quando o cansaço psicológico se instala. Nesse momento, o sujeito passa a tratar seus colegas de trabalho de forma distante, essa atitude pode claramente, ser caracterizada como um mecanismo de defesa. O terceiro sinal é a baixa realização no trabalho, que faz com que o profissional se auto avalie de forma negativa, tornando-se insatisfeito com o seu desenvolvimento no trabalho. Para Trigo et alii (2007, p. 225) as características físicas e psicológicas do burnout podem ser descritas a partir das seguintes características:

\begin{abstract}
A exaustão emocional abrange sentimentos de desesperança, solidão, depressão, raiva, impaciência, irritabilidade, tensão, diminuição de empatia; sensação de baixa energia, fraqueza, preocupação; aumento da suscetibilidade para doenças, cefaléias, náuseas, tensão muscular, dor lombar ou cervical, distúrbios do sono (Cherniss, 1980a; World Health Organization, 1998). O distanciamento afetivo provoca a sensação de alienação em relação aos outros, sendo a presença destes muitas vezes desagradável e não desejada (Cherniss, 1980a; World Health Organization, 1998). Já a baixa realização profissional ou baixa satisfação com o trabalho pode ser descrita como uma sensação de que muito pouco tem sido alcançado e o que é realizado não tem valor (Cherniss, 1980a; World Health Organization, 1998).
\end{abstract}

Os sintomas podem ser físicos e psíquicos e podem ser divididos em quatro classes distintas. Manifestações físicas e psíquicas, alterações corporais e comportamento defensivo. As manifestações físicas são o cansaço constante, problemas com o sono, dores musculares e falta de apetite, as manifestações psíquicas são as faltas de atenção, problemas com memória, frustração e ansiedade. Para identificar as alterações comportamentais é por meio da negligência no trabalho, irritação, dificuldades em se concentrar, necessidade de longos momentos descanso, divergências com os colegas de trabalho e dificuldade em cumprir a carga horária de trabalho.

Os professores da educação infantil estão diariamente em contato com crianças de 0 a 5 anos, auxiliando no desenvolvimento de habilidades sociais e cognitivas. De acordo com Carlotto (2010, p.2) “A profissão docente é considerada pela Organização Internacional do Trabalho (OIT) como uma das mais estressantes, com forte incidência de elementos que conduzem à Síndrome de Burnout.” Atualmente o trabalho do professor não é apenas ensinar, mas também educar e administrar, precisando ser extremamente paciente para atender as demandas dos pais que muitas vezes não participam da rotina dos filhos. Os educadores necessitam utilizar das suas horas de descanso para produzir 
material para suas aulas, lidam com reformas educacionais, muitas vezes possuem problemas com a chefia e colegas de trabalho, entre outras adversidades que precisam lidar no dia a dia, todos possíveis fatores de riscos para o desenvolvimento da síndrome. Gasparini, Barreto e Assunção (2005, p.6) apresentam que:

Os docentes pesquisados citam como fatores de agravamento do problema a quase inexistência de projetos de educação continuada que os capacite para enfrentar a "nova" demanda educacional; o elevado número de alunos por turmas; a infra-estrutura física inadequada; a falta de trabalhos pedagógicos em equipe; o desinteresse da família em acompanhar a trajetória escolar de seus filhos; a indisciplina cada vez maior; a desvalorização profissional e os baixos salários, situações que fogem de seu controle e preparo.

Com o acúmulo de estresse, e de horas de trabalho, muitas vezes também vindo de uma jornada dupla de trabalho, familiar e ocupacional, o educador fica vulnerável aos estímulos aversivos que com o passar dos anos, podem levá-lo a desenvolver a síndrome. A rotina de um professor de educação infantil vai para além do educar, já que, ele deve proporcionar novas experiências no campo do real e do imaginário, estando presente desde o início da vida acadêmica das crianças, antes do ensino fundamental, sendo então, a base que auxilia na continuação do trabalho que é a educação na infância. Segundo apontam Koga et ali (2015), nos dias de hoje é cobrado cada vez mais do professor, no sentido deste ter de conseguir administrar sua unidade de ensino, administrar sua vida pessoal, familiar e financeira. Esse profissional, quase sempre tenta suprir a falta de carinho e atenção para seus alunos, levando-o a uma situação de desgaste com o passar dos anos, acarretando consequências que afetam tanto a si quanto aos que estão ao seu redor, e não somente em relações interpessoais e com os alunos, causando-lhe uma repercussão na própria qualidade do ensino. Conforme aponta Carlotto (2010, p. 2):

O professor pode apresentar planejamento de aula menos frequente e cuidadoso, menos entusiasmo e criatividade em sala de aula, sentir menos simpatia pelos alunos e menos otimismo quanto à avaliação de seu futuro. Pode também se sentir facilmente frustrado pelos problemas ocorridos em sala de aula ou pela falta de progresso de seus alunos, desenvolvendo um comportamento distanciado, resultante da diminuição de seu investimento. Manifesta sentimentos de hostilidade em relação a administradores, alunos, refugiando-se numa visão depreciativa com relação à profissão. Evidencia arrependimento em ter ingressado na profissão e planeja abandonar a mesma.

Conforme essas palavras sugerem, esse conjunto de sentimentos negativos em relação ao seu futuro profissional, como também das suas próprias relações interpessoais acaba por sinalizar o agravamento da síndrome de burnout, lançando o educador em um 
profundo estado de adoecimento psicológico e na falta de um projeto existencial dedicado à docência.

Existem diversos estudos sobre a Síndrome de Burnout em professores, porém poucos estudos foram publicados a respeito deste tema em professores de educação infantil, sendo que eles são a base da educação e, como já pesquisado por Carlotto e Câmara (2008), foram identificados 48 artigos nacionais que abordam a síndrome de burnout, destes selecionados, somente 9 artigos foram realizados com professores da educação básica, sendo 5 de relatos de pesquisa e 4 de revisão teórica. Essas informações mostram a relevância para essa condição da precarização das relações interpessoais e do próprio processo de trabalho no contexto da educação infantil. Por lidarem com crianças, os professores recebem um retorno imediato dos próprios alunos. Contudo, as responsabilidades são maiores quando se lida com questões que muitas vezes ultrapassam os limites da sala de aula, e quase sempre, o resultado de seu trabalho não valorizado pelo Estado e pela sociedade.

\section{Método}

A amostra de participantes consistiu em 6 professores, sendo de áreas específicas e regentes de sala, de uma unidade pré-escolar em uma cidade da Região do Vale do Itajaí em Santa Catarina. Pesquisa aprovada sob parecer do CEP, $\mathrm{n}^{\circ}$ 22542719.4.0000.5370. Para a coleta de dados, foi realizado um levantamento de um conjunto de informações sociodemográficas, profissionais e de lazer. Sobre a percepção deles a respeito do local de trabalho, foi aplicado o instrumento Job Diagnostic Survey (Hackman E Oldham, 1980), que consiste em um questionário dividido em duas seções, sendo 5 questões na primeira seção - variedade de aptidões, identidade do trabalho, significado do trabalho, autonomia e feedback e 10 na segunda referentes aos aspectos das aptidões complexas do trabalho, da estrutura organizacional do trabalho, da avaliação do desempenho do trabalho, da repetição do trabalho, da execução das atividades laborais, da iniciativa dentro do contexto do trabalho, da autonomia do colaborador na tomada de decisões, do grau de feedback no trabalho, da liberdade no mundo do trabalho e, finalmente, do significado existencial do trabalho. Em relação aos sintomas somáticos decorrentes ao trabalho, foi aplicado um questionário com 21 perguntas, destacando-se aquelas 
relacionadas a jornada de trabalho do corpo docente, como também o seu grau de satisfação com as atividades desenvolvidas.

Por último, foi aplicado o instrumento que é o melhor indicado para avaliar a síndrome, o inventário Maslach Burnout Inventory, que consiste em 22 perguntas que medem a exaustão emocional, a despersonalização e a realização pessoal do profissional. Os dados pessoais obtidos ficaram sob sigilo, sendo utilizados apenas os dados necessários para o estudo, que são os que relatam sobre a Síndrome. O questionário foi adaptado para a realidade do local. O MBI é o inventário utilizado para avaliar se existe indicadores da SB que consiste em três dimensões, a exaustão emocional, realização pessoal e a despersonalização. No MBI, as 3 dimensões são distribuídas entre 22 questões que vão avaliar o grau em nível alto, nível médio e nível baixo de cada dimensão o que dará o resultado de qual é nível geral da SB.

A pontuação para todas as perguntas seguem a escala de Likert, sendo (0) nunca, (1) uma vez ao ano ou menos, (2) uma vez ao mês ou menos, (3) algumas vezes ao mês, (4) uma vez por semana, (5) algumas vezes por semana e por último, (6) todos os dias. Os questionários foram previamente explicados e para maior conforto do participante, foram entregues para que pudessem responder em casa.

\section{Resultados}

A respeito dos participantes da pesquisa, 83,33\% são mulheres - de um universo de 06 educadores - com a faixa etária de 40,67 anos, todos possuem ensino superior e a amostra é dividida entre $50 \%$ casada, $50 \%$ solteira e apenas metade da amostra possui filhos. Sobre os dados profissionais, elas trabalham em média 38,17 horas semanais, sendo que $83,33 \%$ cumpre carga horária integral, trabalhando no período matutino e vespertino. $33,33 \%$ possui outro emprego, deixando a carga horária total semanal em média de 42,5 horas. Em relação a faltas justificadas ou não, 50\% respondeu que possuía. Quando questionado sobre a prática de atividade física, 83,33\% responderam que praticavam algum tipo de atividade tendo a frequência média de 3,2 vezes por semana.

É importantes destacarmos que, embora a parcela de participantes da pesquisa fosse reduzida, o enfoque dado a obtenção dos instrumentos de análises provenientes do MBI e do Job Diagnostic Survey, foram ancorados a partir das variáveis sociodemográficas do local de aplicação da pesquisa, uma vez que se tratava de uma 
unidade de educação infantil em um município da Região do Vale do Itajaí que possui cerca de 44.238 habitantes, possuindo ao todo, nove núcleos de Educação Infantil.

Quadro 1 - Sintomas indicadores da Síndrome de Burnout

\begin{tabular}{|c|c|c|c|c|c|c|c|}
\hline SINTOMAS & 0 & 1 & 2 & 3 & 4 & 5 & 6 \\
\hline CEFALEIA & $16,66 \%$ & $16,66 \%$ & $50 \%$ & * & * & $16,66 \%$ & * \\
\hline IRRITABILIDADE FÁCIL & * & * & * & $50 \%$ & $16,66 \%$ & $33,33 \%$ & * \\
\hline $\begin{array}{l}\text { PERDA OU EXCESSO DE } \\
\text { APETITE }\end{array}$ & $16,66 \%$ & * & $33,33 \%$ & $33,33 \%$ & * & $16,66 \%$ & * \\
\hline PRESSÃO ARTERIAL ALTA & $83,33 \%$ & $16,66 \%$ & * & * & * & * & * \\
\hline $\begin{array}{c}\text { DORES NOS OMBROS OU NA } \\
\text { NUCA }\end{array}$ & $16,66 \%$ & * & * & $33,33 \%$ & * & $33,33 \%$ & $16,66 \%$ \\
\hline DOR NO PEITO & $50 \%$ & * & $33,33 \%$ & $16,66 \%$ & * & * & * \\
\hline DIFICULDADE COM O SONO & $16,66 \%$ & $16,66 \%$ & * & $33,33 \%$ & $16,66 \%$ & * & $16,66 \%$ \\
\hline $\begin{array}{c}\text { SENTIMENTO DE CANSAÇO } \\
\text { MENTAL }\end{array}$ & * & * & $16,66 \%$ & $16,66 \%$ & * & $66,66 \%$ & * \\
\hline DIFICULDADES SEXUAIS & $66,66 \%$ & * & * & $33,33 \%$ & * & * & * \\
\hline $\begin{array}{l}\text { POUCO TEMPO PARA SI } \\
\text { MESMO }\end{array}$ & $16,66 \%$ & * & * & * & $33,33 \%$ & $33,33 \%$ & $16,66 \%$ \\
\hline FADIGA GENERALIZADA & $16,66 \%$ & * & $16,66 \%$ & * & $33,33 \%$ & $33,33 \%$ & * \\
\hline PEQUENAS INFECÇÕES & $16,66 \%$ & $50 \%$ & $16,66 \%$ & $16,66 \%$ & * & * & * \\
\hline $\begin{array}{c}\text { AUMENTO DE CONSUMO DE } \\
\text { BEBIDA, CIGARRO OU } \\
\text { SUBSTANCIAS QUÍMICAS }\end{array}$ & $83,33 \%$ & $16,66 \%$ & * & * & * & * & * \\
\hline $\begin{array}{l}\text { DIFICULDADE DE MEMÓRIA E } \\
\text { CONCENTRAÇÃOO }\end{array}$ & $33,33 \%$ & * & * & $33,33 \%$ & * & $33,33 \%$ & * \\
\hline $\begin{array}{c}\text { PROBLEMAS } \\
\text { GASTROINTESTINAIS }\end{array}$ & $50 \%$ & $16,66 \%$ & * & $16,66 \%$ & $16,66 \%$ & * & * \\
\hline PROBLEMAS ALÉRGICOS & $33,33 \%$ & * & $16,66 \%$ & $16,66 \%$ & * & $33,33 \%$ & * \\
\hline $\begin{array}{l}\text { ESTADO DE ACEITAÇÃO } \\
\text { CONTÍNUO }\end{array}$ & * & $16,66 \%$ & $16,66 \%$ & * & * & $50 \%$ & $16,66 \%$ \\
\hline $\begin{array}{c}\text { SENTIR-SE SEM VONTADE SE } \\
\text { COMEÇAR NADA }\end{array}$ & * & $50 \%$ & $16,66 \%$ & $33,33 \%$ & * & * & * \\
\hline PERDA DO SENSO DE HUMOR & $16,66 \%$ & * & $33,33 \%$ & $33,33 \%$ & $16,66 \%$ & * & * \\
\hline GRIPES E RESFRIADOS & $33,33 \%$ & $50 \%$ & * & * & * & $16,66 \%$ & * \\
\hline PERDA DO DESEJO SEXUAL & $50 \%$ & $16,66 \%$ & $16,66 \%$ & $16,66 \%$ & * & * & * \\
\hline
\end{tabular}

A respeito da tabela acima, vemos uma série de sintomas indicadores da Síndrome, tendo em vista que alguns destes sinais podem estar relacionados a outros problemas crônicos que não foram causados pelo trabalho. Os sintomas vão de cefaleia (dores de cabeça) à perda do desejo sexual. Como são respostas pessoais, sua pontuação varia muito, e medicações tomadas podem interferir nos resultados. Lembrando que a pontuação vai de 0 a 6 sendo que zero corresponde a nunca e seis a todos os dias. Os sintomas que mais se destacam pelo maior índice de respostas com uma escala maior são, irritabilidade fácil, com sua maioria respondendo 3 que significa algumas vezes ao mês, sentimento de cansaço mental, com a maioria respondendo 5, algumas vezes por semana, pouco tempo para si, existindo respostas nas três últimos pontos da escala e estado de aceitação continuo, tendo sua resposta igual a 5. Os sintomas que o sujeito pode apresentar são de caráter físico, psíquico, comportamentais e defensivos. 
A exaustão emocional (EE) segundo Pereira (2003) é a sensação de esgotamento físico e mental, o sujeito chegou ao seu limite de possibilidades e sente que não possui mais energia para absolutamente nada

$\mathrm{Na}$ escala, os itens que correspondem a EE são, 1, 2, 3, 6, 8, 13, 14, 16 e 20 e para sua avaliação entre os níveis alto, médio e baixo a somatória das questões devem equivaler a maior que 27 para alto, entre 19 e 26 para médio e menor que 19 para baixo (Maslach, Jackson, 1981).

Quadro 2 - Níveis de exaustão emocional

\begin{tabular}{|c|c|c|}
\hline Nível Alto & Nível Médio & Nível Baixo \\
\hline $66,66 \%$ & $16,66 \%$ & $16,66 \%$ \\
\hline
\end{tabular}

Fonte: Da pesquisa.

Os resultados apresentam que em sua maioria, existe um nível muito alto de exaustão emocional, que pode estar influenciado por vários fatores como por exemplo época do ano de aplicação da escala, tempo de atuação na área, e carga horária trabalhada. Nesse sentido, 04 educadores possuíam carga horária excessiva de trabalho compatível a 40 horas semanais, trabalhando em três turnos associadas as demais responsabilidades familiares e/ ou outras ocupações.

Essa despersonalização para Pereira (2003) sua personalidade sofre ou vem sofrendo alterações, levando profissional a ser mais frio e impessoal com o usuário de seu serviço, passando a demonstrar cinismo e ironia em relação às pessoas e indiferença ao que pode vir acontecer aos demais. Brand (2013, p.52, p.146) afirma que:

[...] na despersonalização, o professor abandona a si mesmo e destitui o caráter afetivo da sua relação com o aluno, adotando um comportamento distante e impessoal, quando não conturbado $e$ de confronto. Frustra-se facilmente com pequenos insucessos em sala de aula, irrita-se frequentemente e critica severamente os alunos e outras pessoas no ambiente de trabalho, apontando-os como potencializadores do seu estado de saúde. [...] quando já não conseguem mais se envolver com os outros, as relações interpessoais são afetadas, tornando-as indiferentes e frias, há um endurecimento afetivo, ou seja, "coisificação" das relações. Em muitos casos, os outros são tidos como os culpados pelo que se passa com ele, mencionado por M7, que não quer ter contato com alunos sob o argumento de que eles a estressam e pioram a sua saúde emocional;

Os itens que correspondem a despersonalização são o 5, 10, 11, 15 e 22 e para a somatória e avaliação os resultados devem ser maiores que 10 para alto, entre 6 e 9 para médio e menor que 6 para baixo. 
Quadro 3 - Níveis correspondentes a despersonalização

\begin{tabular}{|c|c|c|}
\hline Nível Alto & Nível Médio & Nível Baixo \\
\hline $100 \%$ & $*$ & $*$ \\
\hline
\end{tabular}

Fonte: Da pesquisa

O resultado obtido indica um nível alto e total da amostra nesta dimensão, sendo um sinal bem preocupante. Lembrando que outros fatores podem estar associados a este resultado e que, esta dimensão não deve ser avaliada sozinha, mas sim em conjunto com as outras duas.

Pereira (2003) aponta que a realização pessoal, ou profissional, dependendo da fonte, demonstra a insatisfação com as atividades realizadas, sente que não é suficiente, possui baixa autoestima, se sente profissionalmente fracassado, desmotivado, demonstrando baixa eficiência no trabalho, desejando as vezes até abandonar o emprego. Para Brand (2013, p.52, p.147):

\begin{abstract}
$\mathrm{Na}$ baixa realização pessoal, por fim, a autovitimização, a fraqueza presencial, a autodesvalorização, a autossabotagem, a descrença ou fragilidade nos sonhos, nos ideais e nos projetos de ensino assume seu quadro mais severo. O estado de abandono se agrava, o professor deixa de interessar-se pelos eventos de formação, ausenta-se das atividades extraclasse (grupos de estudo, reuniões, conselhos de classe, reuniões com os pais e responsáveis). [...] os sujeitos desistem da profissão, mas não têm outra opção no momento (M1, H3, M4, M5, M7), então, permanecem no trabalho. Este quadro adoece ainda mais os docentes, pois o fogo do animo acabou e esperam o tempo passar, sem saber por que estão num ambiente que só os leva ao sofrimento.
\end{abstract}

Os itens correspondentes à realização pessoal são 4, 7, 9, 12, 17, 18, 19 e 21, para sua somatória, os valores são menor ou igual a 33 para o nível alto, entre 34 e 39 para médio e maior que 40 para nível baixo.

Quadro 4-Níveis correspondentes a realização pessoal

\begin{tabular}{|c|c|c|}
\hline Nível Alto & Nível Médio & Nível Baixo \\
\hline $100 \%$ & $*$ & $*$ \\
\hline
\end{tabular}

Fonte: Da pesquisa.

Pode se observar que os participantes da pesquisa demonstram alto grau de satisfação pessoal. Para ser um indicador da SB, o resultado deveria estar entre médio ou baixo, porém, os outros resultados também são altos. Relembrando, que existem fatores que podem influenciar diretamente nos resultados, como por exemplo o retorno direto 
dado pelo convívio com crianças pequenas. A partir da aplicação do Maslach Burnout Inventory percebe-se que esses educadores, embora considerem-se realizados profissionalmente indicadores preocupantes quanto ao seu cansaço físico e psicológico sendo suscetíveis ao burnout.

\section{Conclusão}

Os resultados mostram um alto nível de exaustão emocional e despersonalização, indicadores do burnout, em contrapartida existe um elevado nível de realização pessoal, o que pode indicar um grau de sofrimento psíquico alto, acompanhado de uma satisfação pelo seu trabalho. Como já escrito anteriormente, este resultado pode estar relacionado pela faixa etária com que estes professores trabalham, alunos entre 4 e 6 anos de idade, relação que passa muito pela afetividade, pois como apontam Rodrigues, Chaves e Carlotto (2010, p. 201):

... pode-se pensar que nessa relação diferenciada do professor de outros niveis de ensino exista uma maior recompensa afetiva. Outra questão pode estar vinculada à opção profissional, uma vez que esse é um nível de ensino, no qual o professor ingressa por gostar de trabalhar especificamente com essa faixa etária.

Essas palavras lavem-nos a questionar o que pode estar causando esse nível de estresse e adoecimento tão alto, mas que, em contrapartida ainda está gerando uma certa satisfação para estes docentes, o que torna necessário mais estudos a respeito deste tema, e com uma amostra de participantes maior.

Este trabalho além de ter tido sua importância foi um grande desafio, pois por mais que a área docente seja uma das mais pesquisadas a respeito da síndrome de burnout, os problemas relacionados a educação infantil são contextualizados a partir das suas especificidades. Segundo Carlotto e Câmara (2008, p.5), em um estudo feito a respeito do burnout:

\footnotetext{
A partir dos dados obtidos verifica-se ainda ser incipiente a produção cientifica sobre a SB no Brasil, tanto em quantidade como nos resultados já obtidos. Esse resultado corrobora a afirmação de Benevides Pereira (2003). Das publicações identificadas, percebe-se a tendência inicial das pesquisas internacionais de estudos com categorias pertencentes à área da saúde e educação. Hoje, sabe-se já ser mais ampla a compreensão do fenômeno. Na década de 90, Maslach e Leiter (1997) alertaram que a SB não tem mais se restringido a profissões ligadas à saúde e à educação. Burnout, a partir de então, passava a ser considerado um fenômeno que afetava praticamente todas as profissões, tendo em vista que quase todas possuem algum tipo de contato interpessoal. Este pode acorrer na forma de atendimento de clientes, consumidores, colegas e também supervisores.
} 
Podemos destacar, que os estudos sobre o adoecimento decorrente da síndrome de burnout em educadores, desperta um interesse crescente por parte da academia, sobretudo no que se refere aos processos de contextualização de políticas públicas voltadas aos professores em sofrimento psicológico. Faz-se necessário, portanto que desenvolvam-se estudos qualitativos e quantitativos em torno da saúde do trabalhador, bem como o desenvolvimento de políticas públicos a respeito de fatores de riscos e formas de prevenção em relação a esse sofrimento.

\section{Referências}

Almeida, Helena, Faísca, Luís, \& Jesus, Saúl Neves de. (2009). Estrutura factorial da versão portuguesa do job diagnostic survey (jds): um estudo confirmatório de validação da escala de características do trabalho. Psicologia, 23(1), 79-102. Disponível:http://www.scielo.mec.pt/scielo.php?script=sci_arttext\&pid=S087420492009000100004\&lng=pt\&nrm=iso\&tlng=pt. Acesso: 20/11/2019.

Andrade, P.S. Cardoso, T. A. O. (2012). Prazer e Dor na Docência: revisão bibliográfica sobre a Síndrome de Burnout. Saúde e Sociedade. 21 (1), 129-140. Disponível: https://www.scielosp.org/pdf/sausoc/2012.v21n1/129-140/pt. Acesso: 14/02/2020.

Brand, R. M. W. (2013). Do mal-estar à readaptação: o que causa o adoecimento e o afastamento da função docente. Tese de Doutorado, Universidade Federal de Pelotas, Pelotas.

Carlotto, M. S. (2014). Prevenção da síndrome de burnout em professores: um relato de experiência. Mudanças: psicologia na saúde. 22 (1), 31-39. Disponível: https://www.metodista.br/revistas/revistasims/index.php/MUD/article/viewFile/4782/4383. Acesso: 14/02/2020.

Carlotto, M. S. Mara, S. G. (2008). Análise da produção científica sobre a Síndrome de Burnout no Brasil. Psico. 39(2), 152-158. Disponível: http://revistaseletronicas.pucrs.br/ojs/index.php/revistapsico/article/view/1461/3035. Acesso: 20/11/2019. 
Carlotto, M. S. (2010). Síndrome de Burnout: diferenças segundo níveis de ensino. Psico. 41(4), 495-502. $2010 . \quad$ Disponível: http://revistaseletronicas.pucrs.br/ojs/index.php/revistapsico/article/view/4881/5958. Acesso: 20/11/2019.

Castro, Fernando Gastal de. (2013). Burnout e complexidade histórica. Revista Psicologia Organizações e Trabalho, 13(1), 49-60. Disponível: http://pepsic.bvsalud.org/scielo.php?script=sci_arttext\&pid=S198466572013000100005\&lng=pt\&tlng=pt. Acesso: 15/02/2020.

Fonte, C. M. S. (2011). Adaptação e validação para português do questionário de copenhagen burnout inventory. Dissertação de Mestrado, Faculdade de Economia da Universidade de Coimbra.

Gasparini S.M. Barreto S.M, Assunção, A. A. (2005). O professor, as condições de trabalho e os efeitos sobre sua saúde. Educação e Pesquisa, 31 (2). Disponível: http://www.scielo.br/pdf/ep/v31n2/a03v31n2.pdf. Acesso: 20/11/2019.

Hackman J. R. Oldham, G. R. (1976). Motivation Through the design of work: test of a theory. Organizational Behaviour and Human Decision Processes. 16(2), 250-279.

Koga, G. K. C, et alii. (2015). Fatores associados a piores níveis na escala de Burnout em professores da educação básica. Cadernos Saúde Coletiva, 23(3), 268-275. Disponível: http://www.scielo.br/pdf/cadsc/v23n3/1414-462X-cadsc-23-3-268.pdf. Acesso: $15 / 02 / 2020$.

Maslach, C. Jackson, S. E. (1981). The Measurement of Experienced Burnout. Journal of Ocuppational Behavior. 2: p.99-113.

Mota, G. S. Alencar, C. M. S. Tapety, F. I. (2016). Síndrome de Burnout em profissionais de saúde: uma revisão bibliográfica da literatura. Revista Eletrônica Acervo Saúde. 5, 237-241.

Oliveira, D. A. (2004). A reestruturação do trabalho docente: precarização e flexibilização. Educação \& Sociedade. 25 (89), 1127-1144. 
Pereira E.F. Teixeira C.S. Santos A. Lopes A.S. Merino, E.A.D. (2009). Qualidade de vida e saúde dos professores de educação básica: discussão do tema e revisão de investigações. Revista Brasileira de Ciências e Movimento. 17 (2), 100-107. Disponível: https://portalrevistas.ucb.br/index.php/RBCM/article/view/1035/1744. Acesso: 20/11/2019.

Pereira, A. (2003). Burnout: Quando o trabalho ameaça o bem-estar do trabalhador. Casa do Psicólogo: São Paulo.

Rodrigues, C. D. Chaves, L. B. Carlotto, M. S. (2010). Síndrome de Burnout em Professores de Educação Pré-Escolar. Interação em Psicologia, 14 (2), 197-204. Disponível: $\quad$ https://revistas.ufpr.br/psicologia/article/view/10009. Acesso: 20/11/2019.

Tostes, M.V. et alii. (2018). Sofrimento mental em Professores do Ensino Público. Saúde Debate. $\quad 42 \quad$ (116), 87-99. Disponível: https://www.scielosp.org/pdf/sdeb/2018.v42n116/87-99/pt. Acesso: 15/02/2020.

Trigo, T. R. et alii. (2007). Síndrome de burnout ou estafa profissional e os transtornos psiquiátricos. Archives of Clinical Psychiatry. 34(5), 223-233. Disponível: http://www.scielo.br/pdf/rpc/v34n5/a04v34n5.pdf. Acesso: 15/02/2020. 